\title{
Timing belt in power transmission and conveying system
}

\author{
Grzegorz Domek ${ }^{*}$, Piotr Krawiec ${ }^{2}$, Michat Wilczyński ${ }^{1}$. \\ ${ }^{1}$ Kzimierz Wielki University in Bydgoszcz (UKW), Faculty of Mathematics, Physics and Technical \\ Sciences, The Institute of Technology, Chodkiewicza 30, 85-061Bydgoszcz, Poland \\ ${ }^{2}$ Poznan University of Technology, Faculty of Machines and Transport, Chair Machine Design \\ Piotrowo 4, 60-138 Poznań, Poland
}

\begin{abstract}
This paper presents the problem of phenomena occurring at the contact of a timing belt and a pulley. Depending on a belt size range these phenomena differ significantly. There is no indication as to what solutions are optimal for drive belts. The analysis of the coupling process and performance tests have shown that the drive belt should have a cord of very good mechanical properties and its raceway side should be made from the material of a low friction coefficient against the pulley material. A flat belt in power transmission and conveying systems cooperates with several elements consisting of timing pulleys, tensioners or guiding rails. In gear with timing belts they depend strongly on characteristics of the process as well as the type of friction. In recent constructions, producers of timing belts are very much concerned about achieving as much slippery surface as possible. The work describes the problem of friction on different surfaces as well as its influence on gear lifetime. Research results confirm that on many surfaces bigger coefficient of friction is expected.
\end{abstract}

Keywords: Timing belts, power transmission belts

\section{Introduction}

A belt drive operation can be represented as a wheel running over a race. This can be compared to the movement of a vehicle wheel on the road, but the road, unlike the belt, is non-deformable. Meshing of a belt and pulleys causes wear to the mating surfaces, mainly due to the rolling friction and sliding friction. To improve the belt life, designers consider improvement of phenomena occurring between a belt and a pulley. In order to reduce the rolling friction, the diameters of pulleys and the hardness of a belt are increased, among others by making them of metal. The sliding friction in a belt transmission gear is associated with compensation of the driving strand elongation on pulleys. To minimize the effects of this phenomenon the elongation-resistant cord is used such as made of steel, polyamide or carbon fiber, thus many belts are named "Carbon" [4, 9].

\footnotetext{
* Corresponding author: gdomek@ukw.edu.pl

Reviewers: Michat Śledziński, Milan Vaško
} 


\section{Coupling between a timing belt and pulleys}

The phenomena occurring in pulleys complicate in the case of timing belt transmission gears. Wear of belts is additionally caused by the process of belt teeth coupling and decoupling with pulley teeth. The attempts to shape teeth of a belt and groves of pulleys so that the coupling is of rolling nature have been unsuccessful so far. Type schedules of rounded and involute teeth (HTD - high torque driver, STD- super torque driver) have not ensured the coupling (meshing) process similar to that in cylindrical transmission gear. They only facilitated sliding of belt teeth into the groves of toothed pulleys $[1,7]$. Comparing the process of a belt tooth coupling with a pulley tooth to the motion of a pendulum of variable length (Fig. 1) one can present the equation of vibrations associated with this process as follows:

$$
\frac{d}{d t}\left[m\left(l_{0}+\Delta l\right)^{2} \dot{\varphi}\right]+m g\left(l_{0}+\Delta l\right) \varphi=0,
$$

or:

$$
m\left(l_{0}+\Delta l\right)^{2} \ddot{\varphi}+2 m\left(l_{0}+\Delta l\right) \Delta l \dot{\varphi}+m g\left(l_{0}+\Delta l\right) \varphi=0 .
$$

In the above equation $m$ - means the belt tooth weight, $l_{0}$ - the distance between the belt tooth center and the central point of meshing "C" (Figure 1), $\Delta l$ - the value of the belt or wheel pitch (depending on whether the moving part is a pulley or a belt) [8].

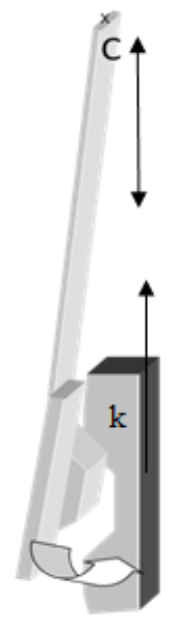

Fig. 1. Comparison of the process of a belt tooth coupling with a pulley tooth to a pendulum, $\mathrm{c}$ - moving pivot point of a tooth, k- moving pulley.

Due to the flexibility of a cord and gradual transfer of load by successive teeth onto the pulley, the pulley and belt teeth coupling process is of "collision" nature. In the belt drive with too little tensioned belt the interference of these teeth occurs and the belt breaks. The teeth of the loaded belt hit the tips of the pulley teeth and then they slip over their sides until full meshing. This phenomenon causes rapid wear of belt teeth and, after long time, also of pulley teeth $[6,10]$. In order to reduce effects of this phenomenon and increase the life of the transmission gear, the friction coefficient of the belt-pulley materials pair must be reduced. Another primary actions include reduction of the strand elongation. Changes of teeth arrangement over the width have been aimed at reduction of noise associated with coupling and improvement of belt guiding on pulleys. From among these solutions least design problems were caused by belts of herringbone teeth (Fig. 2). 


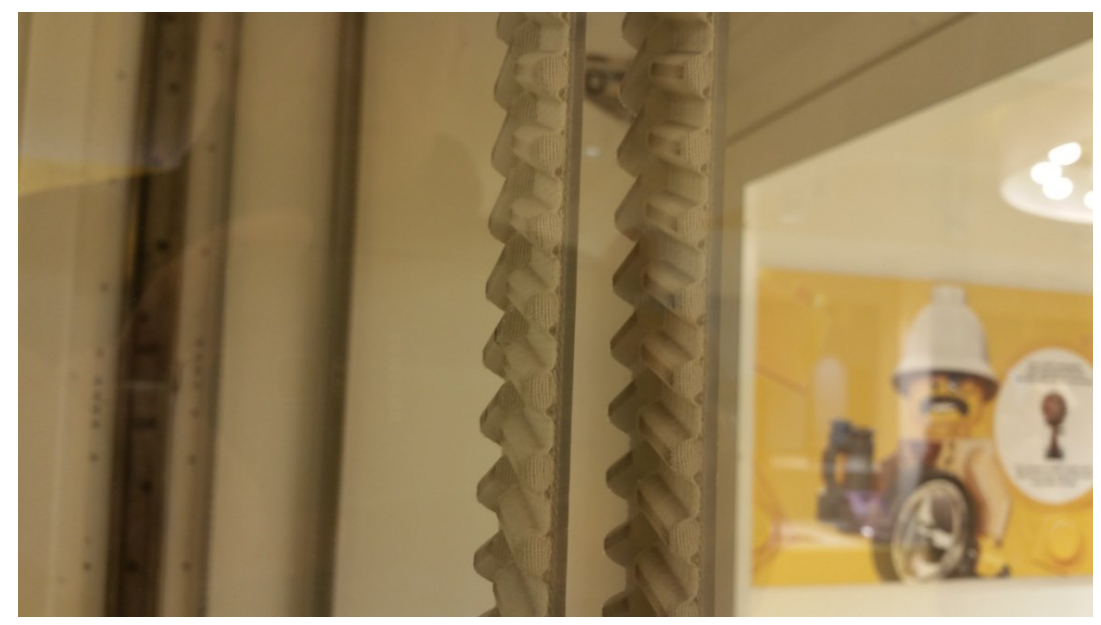

Fig. 2. Herringbone toothed belts in a passenger lift

\section{Timing belt slip over pulleys}

The above-mentioned activities are not identical with measures undertaken for other belt drives. However, the following question must be answered: what is the status of a toothed belt meshing with a pulley and what status are we going to achieve? In most toothed belt drives coupling is of combined form-fitting and friction nature while in structures we most often expect form-fitting $[2,3]$. The nature of the meshing between a belt and a pulley in this case is dependent on the drive design and belt load. In the standard design of most toothed pulleys, the groove is larger than the belt tooth and thus there is a lateral clearance and often a tip clearance between them. If there is no peripheral force causing strand (cord) elongation exceeding the value of the lateral clearance, then it can be assumed that there is only friction coupling in the drive (Fig.3).

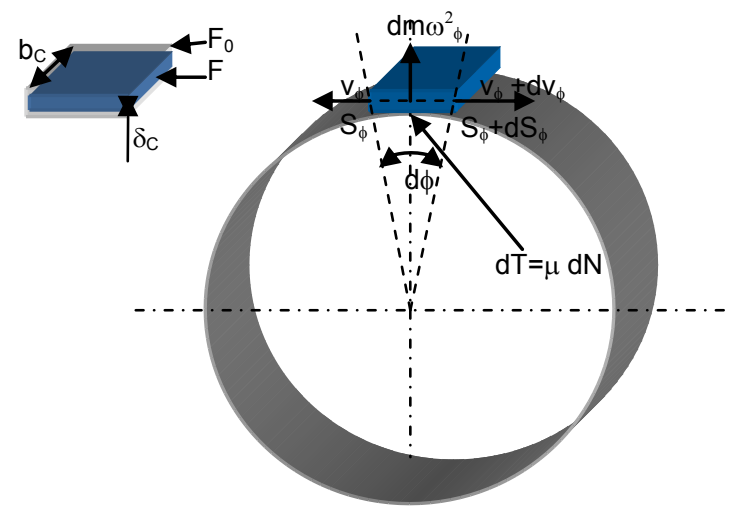

Fig. 3. Contact of an elementary segment of a belt with a pulley

If the belt strand (cord) was non-tensile as in Euler equation, then only friction coupling would occur. The coupling quality depends on the belt on pulley friction factor $\mu_{\mathrm{z}}$ and internal belt friction factor $\mu_{\mathrm{w}}$. The coupling of the belt drive can be considered as follows: 


$$
\frac{d s_{1}}{d s_{2}}=e^{\beta \mu},
$$

where:

$$
\mu=\mu_{\mathrm{z}}+\mu_{\mathrm{w}}
$$

while $\beta$ is the contact angle between the belt and the pulley in radians.

In fact, even a high quality cord is tensile and after exceeding the limit value of the peripheral force the belt starts to cooperate with the wheel by form-fitting coupling. As the load is increasing and thus the belt is elongating, the form-fitting coupling prevails in the toothed drive while the share of friction coupling is negligible. The quality of the coupling is also influenced by the number of teeth at the pulley contact arc [4,5]. Depending on the belt and cord material, the optimum number of teeth varies from 12 to 16. This is the number of teeth, which shall transmit the entire peripheral force from the belt onto the pulley. Successive teeth do not participate in the coupling. Reduced number of teeth participating in the coupling (meshing) process can lead to overloading of the teeth.

\section{The design of the raceway side of a belt}

Belt designers have unsuccessfully been trying to reach the consensus on the desired design features of the raceway side of a belt for years. Polyurethane belts are most often manufactured without additional coating on the raceway side, while rubber belts are covered with additional fabrics. There are many different raceway side coating types available on the market, characterized by different friction coefficients against metal. In the aforementioned cases there is a huge difference between the friction coefficient values of belt material against pulley material. It varies from $0.3-0.4$ in the case of belts without fabric coating (Fig. 4) to 0.008 - 0,01 for "slippery" fabric over steel (Fig. 5,6).

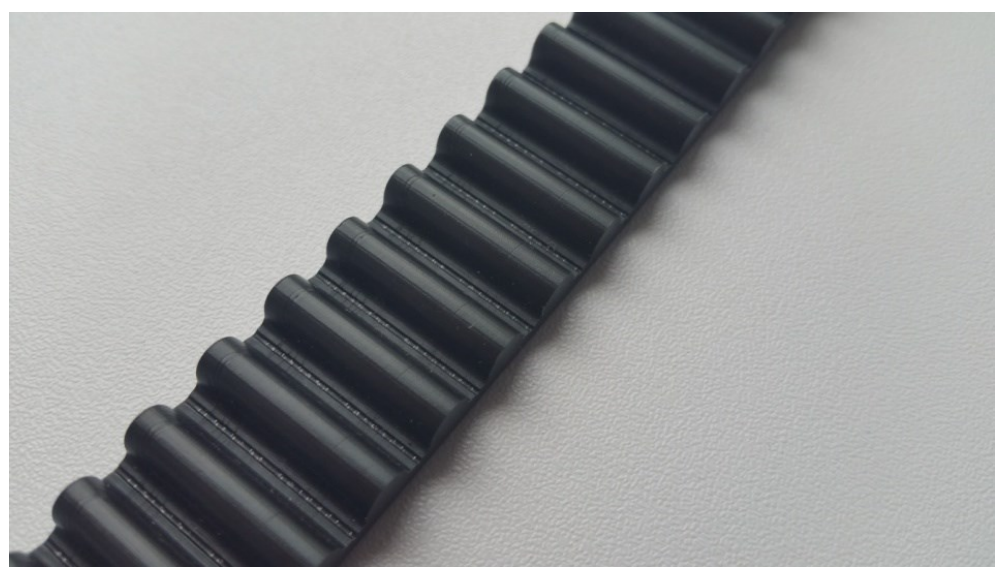

Fig. 4. Polyurethane belt of HTD type without additional coating on the raceway side 


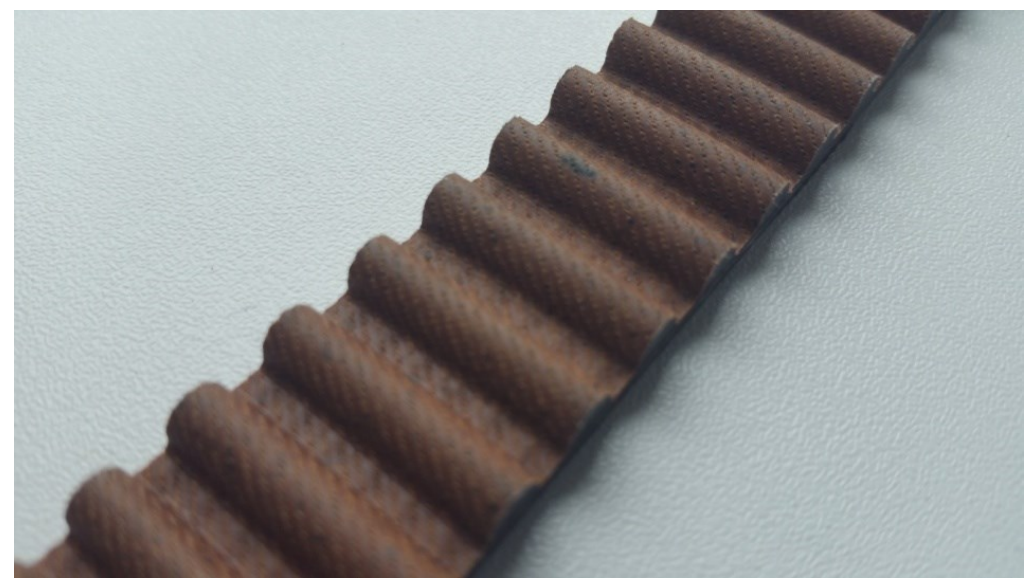

Fig. 5. The rubber HTD belt coated with modern polyester fabric

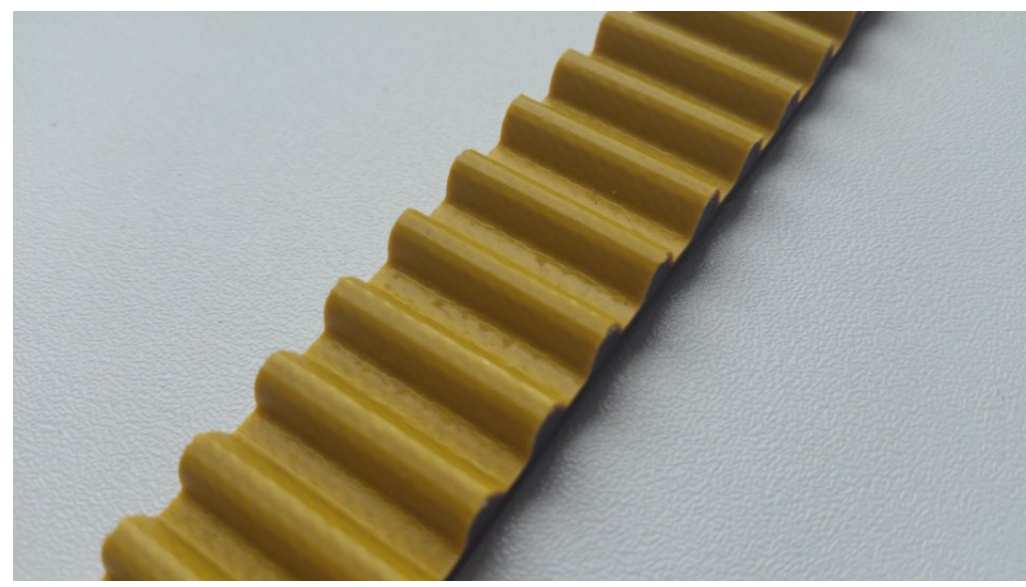

Fig. 6. The Synchrochain belt coated with modern polyamide fabric

The results of performance tests have clearly confirmed that a driving timing belt should be provided with such a raceway so that its friction coefficient against metal is as small as possible, it should have rigid teeth and elongation-resistant cord [11]. The coupling nature in the belt drive will then be close to the form-fitting one and the friction losses will be reduced. However care should be taken to increased rigidity of the belt which can prevent the belt from operating on small diameter pulleys.

\section{Conclusions}

The latest designs of toothed belts aim at reduction of the friction coefficient. Their names include the word "chain". Technical parameters of those belts match the parameters of chains and thus belts are used interchangeably with chains in many applications. However, they have lost an important feature of the belts - i.e. silent-running and currently their use instead of chains reduces the emission of noise to a small extent only. The results of tests confirmed the need to reduce the friction of the driving toothed belt. In applications where the belt is used for control or conveying purposes, these properties must be considered individually. 


\section{References}

1. H. Dressing, F. Holzweissig, Dynamics of Machinery, Theory and Applications. Springer Verlag, Berlin Heidelberg (2010)

2. M. Dudziak, G. Domek, Gear with timing belts in mechatronic drives. Machine Dynamics Problems 28 (3), 83-88 (2004)

3. M. Dudziak, G. Domek, Analysis of Timing Belt's Shape in Meshing with Timing Pulley. Machine Dynamics Problems 30 (2), 32-39 (2006)

4. G. Domek, M. Dudziak, Algorithm for choosing the gears with timing belts. Machine Dynamics Problems 30 (3), 65-71 (2006)

5. G. Domek, A. Kołodziej, The surface conditions of pulleys in use. Machine Dynamics Problems 30 (3), 72-78 (2006)

6. M. Dudziak, G. Domek, Analisis of antitorque in gear with timing belts. Materials Engineering 11 (1), 121-124 (2004)

7. G. Domek, P. Krawiec, Methods of Designing of Timing Belts Pulley. University Reviev, Vol 1, No.3 /2007, Aleksander Dubcek University of Trencin, Izhevsk State Technical University, 15-20 (2007)

8. T. Nagel, Zahnriemengetriebe 2010- neueste Entwicklungen und Trends. Tagungsband zur 14. Internationalen Fachtagung Zahnriemengetriebe, Dresden, 5-8 (2010)

9. R. Perneder, Handbuch Zahnriementechnik. Springer Verlag, Berlin (2009)

10. M. Sága, P. Kopas, M. Uhríčik, Modeling and experimental analysis of the aluminium alloy fatigue damage in the case of bending - torsion loading. Procedia Engineering 48, 599-606 (2012)

11. J. Vollbarth, Anforderungen an Zugtraeger fur Zahnriemen und deren Eigenschaften im Vergleich, Tagungsband zur 14. Internationalen Fachtagung Zahnriemengetriebe, 57-63 (2010) 